\title{
Immunofluorescent localization of the Rab-GAP protein TBC1D4 (AS160) in mouse kidney
}

Lier, Natascha ; Gresko, Nikolay ; Di Chiara, Marianna ; Loffing-Cueni, Dominique ; Loffing, Johannes

\begin{abstract}
TBC1D4 (or AS160) was identified as a Rab-GTPase activating protein (Rab-GAP) that controls insulin-dependent trafficking of the glucose transporter GLUT4 in skeletal muscle cells and in adipocytes. Recent in vitro cell culture studies suggest that TBC1D4 may also regulate the intracellular trafficking of kidney proteins such as the vasopressin-dependent water channel AQP2, the aldosteroneregulated epithelial sodium channel ENaC, and the $\mathrm{Na}(+)-\mathrm{K}(+)$-ATPase. To study the possible role of TBC1D4 in the kidney in vivo, we raised a rabbit polyclonal antibody against TBC1D4 to be used for immunoblotting and immunohistochemical studies. In immunoblots on mouse kidney homogenates, the antibody recognizes specific bands at the expected size of $160 \mathrm{kDa}$ and at lower molecular weights, which are absent in kidneys of TBC1D4 deficient mice. Using a variety of nephron-segment-specific marker proteins, immunohistochemistry reveals TBC1D4 in the cytoplasm of the parietal epithelial cells of Bowman's capsule, the thin and thick limbs of Henle's loop, the distal convoluted tubule, the connecting tubule, and the collecting duct. In the latter, both principal as well as intercalated cells are TBC1D4positive. Thus, with the exception of the proximal tubule, TBC1D4 is highly expressed along the nephron and the collecting duct, where it may interfere with the intracellular trafficking of many renal transport proteins including AQP2, ENaC and $\mathrm{Na}(+)-\mathrm{K}(+)$-ATPase. Hence, TBC1D4 may play an important role for the control of renal ion and water handling and hence for the control of extracellular fluid homeostasis.
\end{abstract}

DOI: https://doi.org/10.1007/s00418-012-0944-1

Posted at the Zurich Open Repository and Archive, University of Zurich

ZORA URL: https://doi.org/10.5167/uzh-63261

Journal Article

Published Version

Originally published at:

Lier, Natascha; Gresko, Nikolay; Di Chiara, Marianna; Loffing-Cueni, Dominique; Loffing, Johannes (2012). Immunofluorescent localization of the Rab-GAP protein TBC1D4 (AS160) in mouse kidney. Histochemistry and Cell Biology, 138(1):101-112.

DOI: https://doi.org/10.1007/s00418-012-0944-1 


\title{
Immunofluorescent localization of the Rab-GAP protein TBC1D4 (AS160) in mouse kidney
}

\author{
Natascha Lier $\cdot$ Nikolay Gresko $\cdot$ Marianna Di Chiara $\cdot$ \\ Dominique Loffing-Cueni $\cdot$ Johannes Loffing
}

Accepted: 14 March 2012/Published online: 31 March 2012

(C) Springer-Verlag 2012

\begin{abstract}
TBC1D4 (or AS160) was identified as a RabGTPase activating protein (Rab-GAP) that controls insulindependent trafficking of the glucose transporter GLUT4 in skeletal muscle cells and in adipocytes. Recent in vitro cell culture studies suggest that TBC1D4 may also regulate the intracellular trafficking of kidney proteins such as the vasopressin-dependent water channel AQP2, the aldosterone-regulated epithelial sodium channel $\mathrm{ENaC}$, and the $\mathrm{Na}^{+}-\mathrm{K}^{+}$-ATPase. To study the possible role of TBC1D4 in the kidney in vivo, we raised a rabbit polyclonal antibody against TBC1D4 to be used for immunoblotting and immunohistochemical studies. In immunoblots on mouse kidney homogenates, the antibody recognizes specific bands at the expected size of $160 \mathrm{kDa}$ and at lower molecular weights, which are absent in kidneys of TBC1D4 deficient mice. Using a variety of nephron-segment-specific marker proteins, immunohistochemistry reveals TBC1D4 in the cytoplasm of the parietal epithelial cells of Bowman's capsule, the thin and thick limbs of Henle's loop, the distal convoluted tubule, the connecting tubule, and the collecting duct. In the latter, both principal as well as intercalated cells are TBC1D4-positive. Thus, with the exception of the proximal tubule, TBC1D4 is highly expressed along the nephron and the collecting duct, where it may interfere with the intracellular trafficking of many renal transport proteins including $\mathrm{AQP} 2, \mathrm{ENaC}$ and $\mathrm{Na}^{+}-\mathrm{K}^{+}$-ATPase. Hence, TBC1D4 may play an important
\end{abstract}

N. Lier · N. Gresko - M. Di Chiara - D. Loffing-Cueni ·

J. Loffing ( $\square)$

Institute of Anatomy and Zurich Center for Integrative

Human Physiology, University of Zurich,

Winterthurerstrasse 190, 8057 Zurich, Switzerland

e-mail: johannes.loffing@anatom.uzh.ch role for the control of renal ion and water handling and hence for the control of extracellular fluid homeostasis.

Keywords Rab proteins - Distal tubule - Transport . Amiloride $\cdot$ Thiazide

\section{Introduction}

The kidney plays an important role for whole-body homeostasis by regulated filtration, excretion and reabsorption of water, solutes and electrolytes along the nephron. These transport processes are largely coupled to the activity of transport proteins and channels in the apical and basolateral plasma membrane of the epithelial cells lining the tubular lumen. In recent years, most of these transport proteins have been identified, which allowed to study their regulation at the molecular level. Interestingly, the activity of many of these proteins is regulated, at least in part, by changes in their cell surface abundance. For example, in the proximal tubule (PT), rapid endocytosis of the NaPi-IIa-cotransporter regulates phosphate reabsorption in response to parathyroid hormone (PTH) or increased dietary phosphate intake (Murer et al. 2003). Likewise, altered cell surface abundances of the bumetanide-sensitive $\mathrm{NaK} 2 \mathrm{Cl}$ cotransporter (NKCC2) and of the thiazide-sensitive $\mathrm{NaCl}$ cotransporter (NCC) contribute to the vasopressin- and angiotensin II-dependent control of sodium reabsorption in the thick ascending limb (TAL) and the distal convoluted tubule (DCT), respectively (Mount 2006; Mutig et al. 2010; Sandberg et al. 2007). In the downstream localized connecting tubule (CNT) and collecting duct (CD), the vasopressin- and aldosterone-dependent stimulation of water and sodium reabsorption relies on the rapid translocation of aquaporin-2 (AQP2) water channels and 
amiloride-sensitive epithelial sodium channels (ENaC) from intracellular storage sites to the luminal membrane (Loffing and Korbmacher 2009; Nielsen et al. 2002). Also, the electrogenic hydrogen pump $\left(\mathrm{H}^{+}\right.$-ATPase $)$in the intercalated cells (IC) of cortical and medullary collecting ducts is regulated by rapid insertion in, or removal from, the plasma membrane in response to an altered acid-base status (Wagner et al. 2004). Finally, the basolateral sodium pump $\left(\mathrm{Na}^{+}-\mathrm{K}^{+}\right.$-ATPase) can reside in latent intracellular compartments, from where it is translocated to its predominant localization at the basolateral plasma membrane (Feraille and Doucet 2001). Thus, regulated trafficking of membrane proteins contributes importantly to the control of renal solutes and water transport along the entire nephron. However, the underlying molecular mechanisms that control and mediate the intracellular protein transport are only incompletely understood.

Intracellular protein trafficking involves budding of membrane protein bearing vesicles from a donor compartment, their intracellular transport along the cytoskeleton and finally the docking and fusion with the membrane of an acceptor compartment. Rab proteins, members of the family of small GTPases, control many of these events by switching from an inactive (GDP-bound) to an active (GTP-bound) conformation (Stenmark and Olkkonen 2001). Guanine nucleotide exchange factors (GEF) activate Rab proteins and thereby promote their binding to the cytoplasmic face of the membrane of organelles, vesicles and the plasma membrane, whereas GTPase activating proteins (GAP) terminate Rab protein activity by stimulation of Rab protein-dependent GTP hydrolysis (Barr and Lambright 2010; Frasa et al. 2012). One of these Rab-GAP proteins is TBC1D4 that belongs to the family of TBC (Tre-2/Bub2/Cdc16) domain-containing proteins (Frasa et al. 2012), which were previously implicated in the regulation of cell growth and differentiation (White et al. 2000). Numerous recent studies established TBC1D4 as an important player in the insulin-dependent regulation of glucose uptake in adipocytes and skeletal muscle cells. TBC1D4 is a protein of $160 \mathrm{kDa}$ that becomes rapidly phosphorylated by $\mathrm{PKB} / \mathrm{Akt}$ in response to insulin stimulation. Therefore, TBC1D4 is also referred to as Akt substrate of $160 \mathrm{kDa}$ (AS160) (Sano et al. 2003). In adipocytes and skeletal muscle cells, TBC1D4 (AS160) is thought to retain the insulindependent glucose transporter GLUT4 in an intracellular storage compartment by deactivation of Rab proteins important for GLUT4 cell surface targeting. Insulin-induced phosphorylation by PKB/Akt allows binding of 14-3-3 proteins, which inactivates TBC1D4 and releases GLUT4 from intracellular retention and hence increases GLUT4 cell surface abundance (Eguez et al. 2005; Kane et al. 2002; Larance et al. 2005; Miinea et al. 2005; Sano et al. 2003). Interestingly, TBC1D4 is expressed not only in fat and skeletal muscle, but also in many other organs including the kidney (Kane et al.
2002; Nagase et al. 1998). Recent in vitro studies indicated that TBC1D4 may participate in the regulation of ENaC (Liang et al. 2010), $\mathrm{Na}^{+}-\mathrm{K}^{+}$-ATPase (Alves et al. 2010) and AQP-2 (Jung and Kwon 2010; Kim et al. 2011) in renal epithelia. However, although expression of TBC1D4 mRNA in the kidney has been reported (Kane et al. 2002; Nagase et al. 1998), the precise cellular and subcellular localization of TBC1D4 in the kidney in vivo has not yet been studied. However, knowledge about the intrarenal distribution of TBC1D4 is important to better understand its potential physiological role in the kidney. Therefore, the aim of the present study is to provide a detailed immunolocalization of TBC1D4 along the mouse nephron using a novel TBC1D4 antibody together with a variety of antibodies against wellestablished marker molecules, which allows unequivocal identification of nephron segments.

\section{Materials and methods}

Animals

Animal studies were conducted in accordance with the Swiss animal welfare regulations and after written consent of the veterinarian office of the Canton of Zurich, Switzerland. C57/B16 mice were obtained from Harlan (Horst, The Netherlands). The TBC1D4-deficient mice (B6129S5$\mathrm{Tbc} 1 \mathrm{~d} 4^{\mathrm{tm} 1 \mathrm{Lex}}$ ) had been generated by targeted deletion of part of exon 1 of the TBC1D4 gene. To the best of our knowledge, data on these mice have not yet been published. However, details on the targeting strategy are available via the website of Taconic (Hudson, NY, USA) at http://www.taconic.com. For our experiments, the TBC1D4-deficient mice were purchased from the Texas Institute of Genomic Medicine (Houston, TX, USA). The C56/B16 wildtype mice and the 129/SvEv-C57BL/6 TBC1D4-deficient mice were then crossed to a mixed 129/SvEv-C57BL/6 mouse background. Two sets of mice with each three wildtype and three TBC1D4-deficient adult male were used either for immunoblotting or for immunohistochemistry. Mice had free access to standard lab chow and tap water. TBC1D4-deficient mice appeared healthy and did not reveal any gross abnormalities when compared to the wildtype littermates.

\section{Generation of anti-TBC1D4 antibody}

The anti-TBC1D4 antibody was generated by immunizing rabbits with a synthetic peptide corresponding to the C-terminal amino-acid sequence of mouse TBC1D4 (CPTNDKAKAGNKP). The obtained antisera were subsequently affinity purified against the peptide using standard procedures. Peptide synthesis, immunization of rabbits 
and antibody purification were custom made (Pineda $\mathrm{Ab}$ Service, Berlin, Germany).

\section{Western blot}

Total kidney homogenates were prepared as described (Busque and Wagner 2009). Protein concentrations in the tissue homogenates were assessed by a Bradford assay. After denaturation of the proteins $\left(5 \mathrm{~min}, 95^{\circ} \mathrm{C}\right)$ with Laemmli loading buffer (supplemented with $\beta$-mercaptoethanol, $500 \mathrm{mM}$ ), $25 \mu \mathrm{g}$ of total protein lysates was separated by SDS-PAGE and electrophoretically transferred to nitrocellulose membranes (Whatman Protran, Millipore). After transfer, membranes were incubated in LI-COR (LI-COR Biosciences, Bad Homburg, Germany) membrane blocking buffer (30 min, rolling shaker, RT) and incubated with primary antibodies overnight at $4{ }^{\circ} \mathrm{C}$. Binding of the primary antibody was visualized using Infra red dye-conjugated secondary IgG (LI-COR) and an Odyssey infrared-scanner detection system (LI-COR).

\section{Fixation and tissue processing}

The kidneys of anesthetized mice were fixed by intravascular perfusion of $3 \%$ paraformaldehyde as described in detail previously (Loffing et al. 2001). Kidneys were removed, cut into coronal tissue slices of 2- to 3-mm thickness, mounted on small cork disks, frozen in liquid propane and then stored at $-80{ }^{\circ} \mathrm{C}$ until use (Loffing et al. 2001).

\section{Immunohistochemistry}

Serial sections (3-5 $\mu \mathrm{m}$ thick) of the kidneys were cut in a cryostat, placed on chrome-alum gelatin-coated glassslides, thawed and stored in PBS until use and then pretreated for 10 min with $10 \%$ normal goat serum in PBS. Thereafter, the sections were incubated overnight in a humidified chamber at $4{ }^{\circ} \mathrm{C}$ with the primary antibodies (Table 1), diluted in PBS- $0.5 \%$ bovine serum albumin. Immunostaining of the serial sections with the primary antibody occurred in the following order: (1) Anti-NKCC2; (2) anti-TBC1D4 (AS160); (3) anti-NCC; (4) anti-TBC1D4
(AS160); (5) anti- $\gamma \mathrm{ENaC}$; (6) anti-TBC1D4 (AS160); (7) anti-AQP2. In addition to these polyclonal rabbit antibodies, each kidney section was also stained with a mouse monoclonal antibody against calbindin $\mathrm{D}_{28 \mathrm{k}}$. This sequential staining protocol allowed us to evaluate the distribution of TBC1D4 in a given renal tubule along several consecutive sections. For unequivocal identification of proximal tubules, some sections were co-stained with FITC-conjugated phalloidin (dilution 1:50, Molecular probes Inc.) that strongly binds to the f-actin cytoskeleton of the proximal tubule brush border. For identification of intercalated cells, separate sections were co-stained with mouse monoclonal antibodies against the bovine $\mathrm{H}^{+}$-ATPase (dilution 1:4). To detect the binding sites of the primary antibodies, the sections were incubated in a humidified chamber at room temperature during $1 \mathrm{~h}$ with the following secondary antibodies: Cy3-conjugated goat anti-rabbit IgG (Jackson Immuno Research Laboratories, West Grove, PA, USA) and FITC-conjugated goat anti-mouse IgG (Jackson Immuno Research Laboratories). 4,6-diamidino-2-phenylindol (DAPI, 1:1000; Sigma-Aldrich, Steinheim) was added to the working dilution of the secondary antibodies for nuclear staining. The coverslips were mounted using DAKO-Glycergel (DakoCytomation, Denmark), to which $2.5 \%$ 1,4-diazabicyclo(2,2,2)octane (DABCO; Sigma, Steinheim) was added as fading retardant. Slides were examined and images were captured with the $5 \times$ and $40 \times$ objectives of a fluorescence microscope (Leica DM6000 B). Images were acquired with a charge-coupled device camera and processed by Adobe Photoshop CS3 and Microsoft PowerPoint software. In separate experiments, we also tested different antigen retrieval techniques including microwave heating (Werner et al. 1996) and SDS-pretreatment (Brown et al. 1996). These antigen retrieval techniques did not improve the immunostainings and did not reveal TBC1D4 in other cell types than under standard conditions.

\section{Segment definitions}

We used the established distribution pattern of certain marker proteins to define the specific segments of the
Table 1 Primary antibodies used for immunohistochemistry

$N K C C 2 \mathrm{Na}^{+}-\mathrm{K}^{+}-2 \mathrm{Cl}^{-}$ cotransporter, $\mathrm{NCC} \mathrm{Na}^{+}-\mathrm{Cl}^{-}$ cotransporter, $\mathrm{ENaC}$ amiloridesensitive epithelial $\mathrm{Na}^{+}$ channel, $A Q P 2$ aquaporin 2, $H^{+}$-ATPase vacuolar proton ATPase, $C B 28$ calbindin $\mathrm{D}_{28 \mathrm{~K}}$

\begin{tabular}{llll}
\hline Antibody & Host & Dilution & Description \\
\hline Anti-TBC1D4 & Rabbit & $1: 5,000$ & This study \\
Anti-NKCC2 & Rabbit & $1: 40,000$ & Wagner et al. (2008) \\
Anti-NCC & Rabbit & $1: 2,000$ & Loffing et al. (2004) \\
Anti- $\gamma \mathrm{ENaC}$ & Rabbit & $1: 20,000$ & Wagner et al. (2008) \\
Anti-AQP2 & Rabbit & $1: 20,000$ & Wagner et al. (2008) \\
Anti-H ${ }^{+}$-ATPase & Mouse & $1: 4$ & Hemken et al. (1992) \\
Anti-CB28 & Mouse & $1: 20,000$ & Swant, Bellinzona, CH \\
\hline
\end{tabular}


mouse nephron. A well-developed brush border is indicative for the proximal tubule. The expression of NKCC2 is the hallmark of the thick ascending limb (TAL) and the presence of NCC characterizes the distal convoluted tubule (DCT), which can be subdivided into an early ENaC-negative portion (DCT1) and a late ENaC-positive portion (DCT2) (Loffing et al. 2000; Schmitt et al. 1999). The CNT and cortical CD (CCD) are NCC-negative, but ENaC- and AQP2 positive (Kishore et al. 1996; Loffing and Kaissling 2003). CNT and CCD can be distinguished based on their different histotopographical localization in the cortical labyrinth and medullary ray, respectively (Reilly and Ellison 2000). The two main subtypes of intercalated cells were defined with the aid of an antibody against the vacuolar $\mathrm{H}^{+}$-ATPase, which is found in type A and type B intercalated cells preferentially at the apical and basolateral plasma membrane, respectively (Kim et al. 1999).

\section{Results}

\section{Characterization of the TBC1D4 antibody}

The affinity-purified anti-TBC1D4 antibody (Pineda) was characterized by western blot and immunohistochemistry, using TBC1D4 wildtype and knockout mice. The immunoblot showed a strong band of the expected size at $160 \mathrm{kDa}$ and several weaker bands at lower molecular weights. With the exception of one band at about $100 \mathrm{kDa}$, the bands did not appear in kidney preparations from TBC1D4-deficient mice indicating that they represent TBC1D4 (Fig. 1a). The nature of the low molecular weight forms of TBC1D4 is unclear and may represent splice variants. Alternative splicing of the TBC1D4 gene has been described (Baus et al. 2008). Likewise, the ENSEMBL database (http://www.ensembl.org) lists seven different TBC1D4 transcripts. Six of these transcripts are thought to be protein coding. Four encompass the $\mathrm{C}$-terminal peptide sequence against which our TBC1D4 antibody is directed. The other two variants are likely not detected by our antibody. In immunohistochemical studies (Fig. 1c, d), our TBC1D4 antibody showed a strong immunofluorescent signal in several tubules in the renal cortex and renal medulla. The staining was completely absent from kidneys of TBC1D4-deficient mice further confirming that the antibody specifically recognizes TBC1D4 in both immunoblotting and immunohistochemical studies (Fig. 1).

\section{Distribution of TBC1D4 in the kidney}

Overviews on the mouse renal cortex (Fig. 2) reveal that TBC1D4 is expressed in NKCC2- and NCC-positive renal tubules, in a few NKCC2- and NCC-negative tubules and

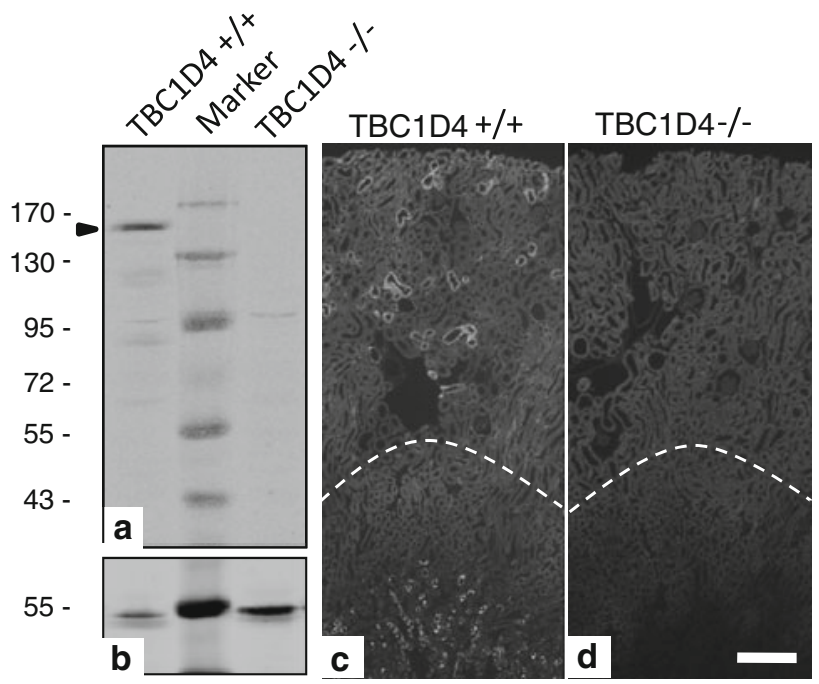

Fig. 1 Characterization of affinity-purified rabbit anti-TBC1D4 antibodies by immunoblotting (a, b) and immunohistochemistry (c, d). a In tissue homogenates of wildtype $(+/+)$ mice, the antiTBC1D4 antibody detects a strong band of the expected size of $160 \mathrm{kDa}$ (arrowhead) and several additional bands at lower molecular weights. With the exception of one band at about $100 \mathrm{kDa}$, all bands are absent in kidney homogenates of TBC1D4-deficient mice (-/-). b Detection of $\beta$-tubulin $(1: 4,000)$ served to confirm equal protein loading. c In immunohistochemistry, TBC1D4 is clearly abundant in tubules of the renal cortex and the inner stripe of the renal outer medulla of wildtype $(+/+)$ mice. d Kidneys of TBC1D4-deficient mice $(-/-)$ are unstained. The border between the renal cortex and the outer medulla is indicated by a dashed line. Scale bar $\sim 200 \mu \mathrm{m}$

around the renal glomeruli. The majority of renal tubules, which represent proximal tubules, is TBC1D4-negative.

At high magnification, it becomes evident that in the renal corpuscle, TBC1D4 is highly abundant only in the cytoplasm of the parietal epithelial cell of Bowman's capsule, while the other glomerular cell types (i.e. podocytes, mesangial cells and endothelial cells) appear to be TBC1D4-negative. The proximal tubule, which can be easily discerned by its f-actin-rich brush border, is also TBC1D4-negative (Fig. 3a, b). Only the very first proximal tubule cells, directly adjacent to the Bowman's capsule, show occasionally some TBC1D4-immunoreactivity. The rest of the proximal tubule as well as the entire straight proximal tubule does not show any TBC1D4 immunoreactivity (Fig. 3a, c). In contrast, TBC1D4 is highly abundant along the entire thin limbs, which is already strong in the cytoplasm of the first descending thin limb (DTL) cells (Fig. 3c, d) and remains intense until the end of the ascending thin limb (ATL) up to the transition to the NKCC2-positive thick ascending limb (TAL) (Fig. 3e, f).

In contrast to the strongly stained DTL cells, the first TAL cells show only a very weak, if any TBC1D4 immunostaining (Fig. 3e). However, the TBC1D4-related immunofluorescent signal increases along the axis of the 

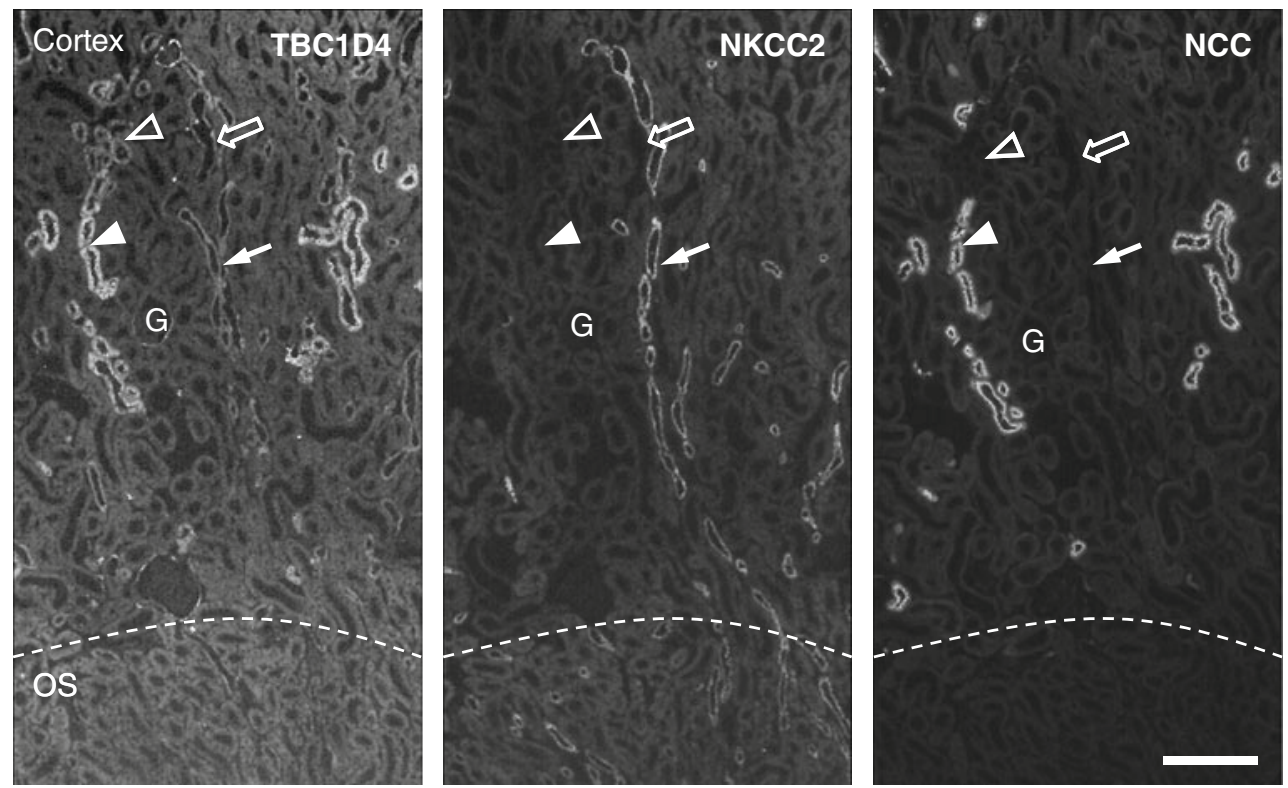

Fig. 2 Localization of TBC1D4 in the renal cortex and the outer stripe (OS) of the outer medulla of mouse kidneys. Consecutive cryosections immunostained with polyclonal antibodies against TBC1D4, NKCC2, and NCC. TBC1D4 is present in cortical distal tubules that are either NKCC2-positive (closed arrows), NCCpositive (closed arrowheads), or NKCC2/NCC-negative. The latter are located in the cortical labyrinth (open arrowheads) and in

TAL in tubular flow direction (Fig. 4a). Consistently, TBC1D4 immunostaining is usually more pronounced in the cortical (Fig. 4b, c) than in the medullary TAL (Fig. 4d, e). In the cortical TAL, the macula densa cells show the strongest TBC1D4 immunostaining and can be thus easily distinguished from the weaker stained surrounding TAL cells (Fig. 4f, g).

The transition from the TAL to the distal convoluted tubule (DCT) is characterized by a sharp increase in the epithelial height and by an abrupt replacement of the TALspecific NKCC2 by the DCT-specific NCC. Consistent with the clear demarcation between TAL and DCT, TBC1D4 immunoreactivity rises abruptly from the last TAL to the first DCT cell (Fig. 5 a-c). TBC1D4 protein abundance remains high along the entire early DCT (DCT1), but starts to decrease in the end portion of the DCT (DCT2) and even further along the CNT. Co-immunostainings with calbindin $\mathrm{D}_{28 \mathrm{~K}}$ (CB28) eased unequivocal identification of DCT1, DCT2 and CNT based on the different CB-staining intensities and prevalence of CB28-negative intercalated cells in the three segments (Fig. 5 d-h). Interestingly, along DCT2 and CNT, apical $\gamma \mathrm{ENaC}$ localization and TBC1D4 abundance decrease in parallel (Fig. 6a, b). TBC1D4 remains detectable along the CNT, CCD and the outer medullary collecting duct (OMCD) of the outer stripe, but is barely detectable in the OMCD of the inner stripe (Fig. $6 \mathrm{c}-\mathrm{q}$ ). Interestingly, medullary rays (open arrows). Moreover, glomeruli (G) are surrounded by a rim of TBC1D4 immunoreactivity. Note the different TBC1D4-staining intensities between NKCC2-positive TALs, NCCpositive DCTs, and the NKCC2/NCC-negative CNTs and CCDs. The dashed lines indicate the border between the renal cortex and the outer stripe (OS) of the outer medulla. Scale bar $\sim 200 \mu \mathrm{m}$

in $\mathrm{CNT}$ and $\mathrm{CD}$, both the ENaC- and AQP2-positive segment-specific cells as well as the ENaC- and AQP-2 negative intercalated cells reveal TBC1D4. Double immunostainings with antibodies against TBC1D4 and $\mathrm{H}^{+}$-ATPase show that all subtypes of intercalated cells express TBC1D4 (Fig. 6 i-m). However, staining intensities in the cell types vary along the collecting system. In the CNT, intercalated and the segment-specific CNT cells express similar high levels of TBC1D4. However, along the cortical collecting duct, TBC1D4 immunostaining decreases in principal cells and in type A intercalated cells and remains high in type B intercalated cells only. Along the medullary collecting duct, TBC1D4 immunostaining disappears in all cell types (Fig. $6 \mathrm{n}-\mathrm{q}$ ).

\section{Discussion}

Our study provides a comprehensive analysis of the localization and abundance of TBC1D4 along the mouse nephron. Using a variety of nephron markers, we show that TBC1D4 is expressed in the cytoplasm of epithelial cells lining the parietal layer of Bowman's capsule, the thin limbs, the TAL, the DCT, the CNT and the CCD. Moreover, our study reveals marked differences in TBC1D4 protein abundance between cell types and along the axis of the nephron, which point to a differential role of TBC1D4 

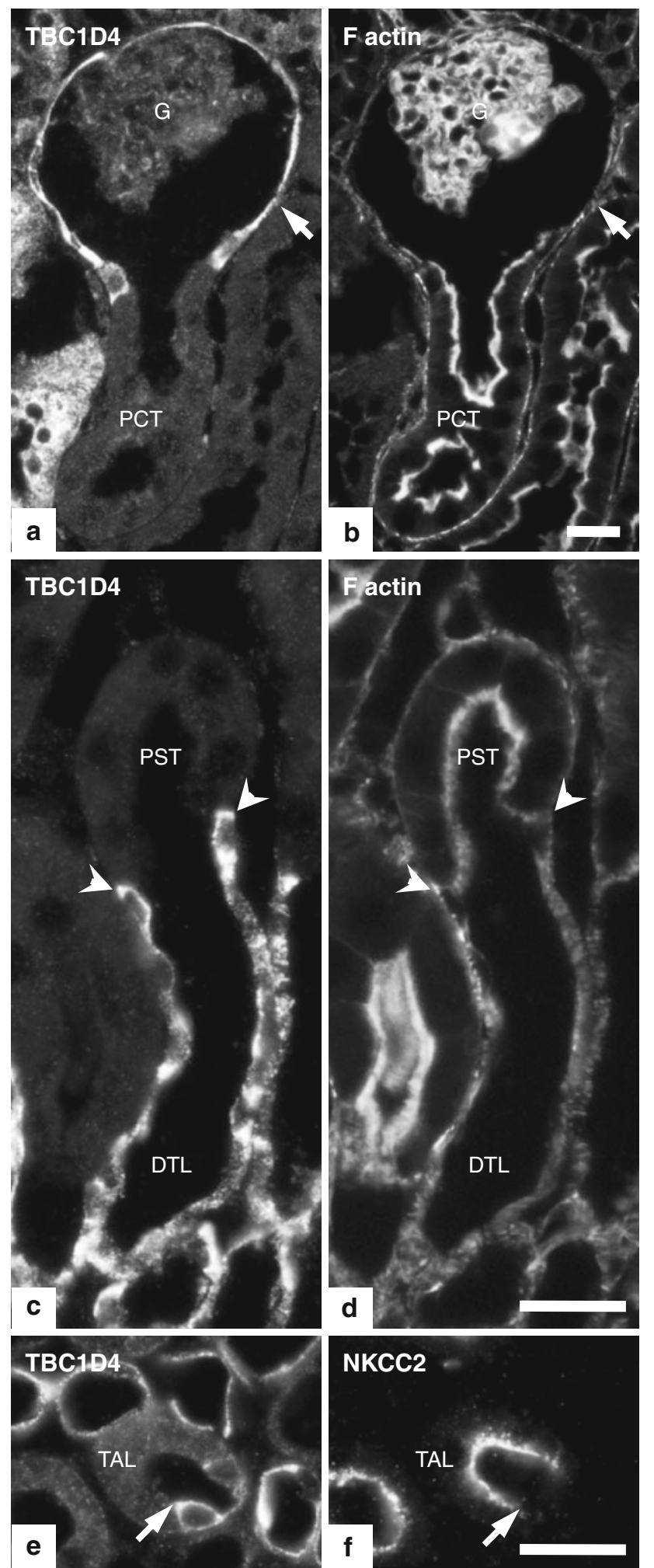

function along the renal tubule. Our findings are depicted schematically in Fig. 7.

Previous studies reported TBC1D4 mRNA expression in several organs including brain, heart, pancreas and the
4 Fig. 3 Distribution of TBC1D4 in glomeruli and thin limbs. a-d Cryosections stained with a polyclonal antibody against TBC1D4 and phalloidin-FITC for detection of f-actin. a, b TBC1D4 is highly abundant in the cytoplasm of the parietal epithelial cells (arrow) of the glomerulus $(\mathrm{G})$, but is undetectable in proximal convoluted tubules (PCT), which are well discernible from other tubules by their f-actin rich brush border. c, $\mathbf{d}$ TBC1D4 is undetectable in the f-actinrich proximal straight tubule (PST). The sharp morphological transition from PST to the thin descending limbs (DTL) coincides with a strong onset of TBC1D4 immunoreactivity in the epithelial cells of the DTL. e, f Consecutive cryosections immunostained for TBC1D4 and NKCC2. The strong TBC1D4-immunoreactivity in the thin limb ceases abruptly at the well-discernible transition from the ascending thin limb (arrow) to the NKCC2-positive medullary thick ascending limb (TAL). Scale bars $\sim 30 \mu \mathrm{m}$

kidney (Kane et al. 2002; Nagase et al. 1998). Now, we show by immunoblotting and immunohistochemistry that TBC1D4 is highly abundant also at the protein level in the mouse kidney. With the exception of the proximal tubule, TBC1D4 protein is found along the entire nephron with the highest expression levels in Bowman's capsule, thin limbs and distal convoluted tubules. In most cells, TBC1D4 shows a diffuse intracellular localization, which corresponds to the subcellular localization of TBC1D4 in cells in vitro as reported previously (Alves et al. 2010). The limited optical resolution of light microscopy does not allow us to assign the intracellular staining pattern to specific cell organelles, but the predominant diffuse intracellular localization supports the idea that TBC1D4 is a cytosolic Rab-GAP protein that controls membrane trafficking at different intracellular sites. In fact, previous in vitro studies suggested that TBC1D4 has Rab-GAP activity towards Rab proteins 2a, 8a, 10, and 14 (Ishikura et al. 2007; Miinea et al. 2005; Sano et al. 2008), which are known to regulate protein trafficking at many organelles including the endoplasmic reticulum (ER), the Golgi apparatus, sorting endosomes, and the plasma membrane (Takai et al. 2001). Moreover, certain Rab proteins (e.g. Rab8, 10, 11, 23) have been implicated in ciliary trafficking and ciliopathies in various cell types including renal epithelia (Lim et al. 2011). The Rab proteins targeted by TBC1D4 in the kidney in vivo are unknown, but several Rab proteins, including the ones listed above, are expressed along the renal tubular system (Chabardes-Garonne et al. 2003; Pradervand et al. 2010).

TBC1D4 was initially identified as an insulin-regulated protein that controls the intracellular trafficking of the glucose transporter GLUT4 in adipocytes and skeletal muscle cells (Kane et al. 2002; Sano et al. 2003). In the kidney, epithelial glucose transport is thought to occur mainly in the proximal tubule to recover filtered glucose from the urine via the apical sodium-dependent glucose transporter SGLT2 (Mather and Pollock 2011). However, there is also evidence for GLUT4-mediated renal glucose 

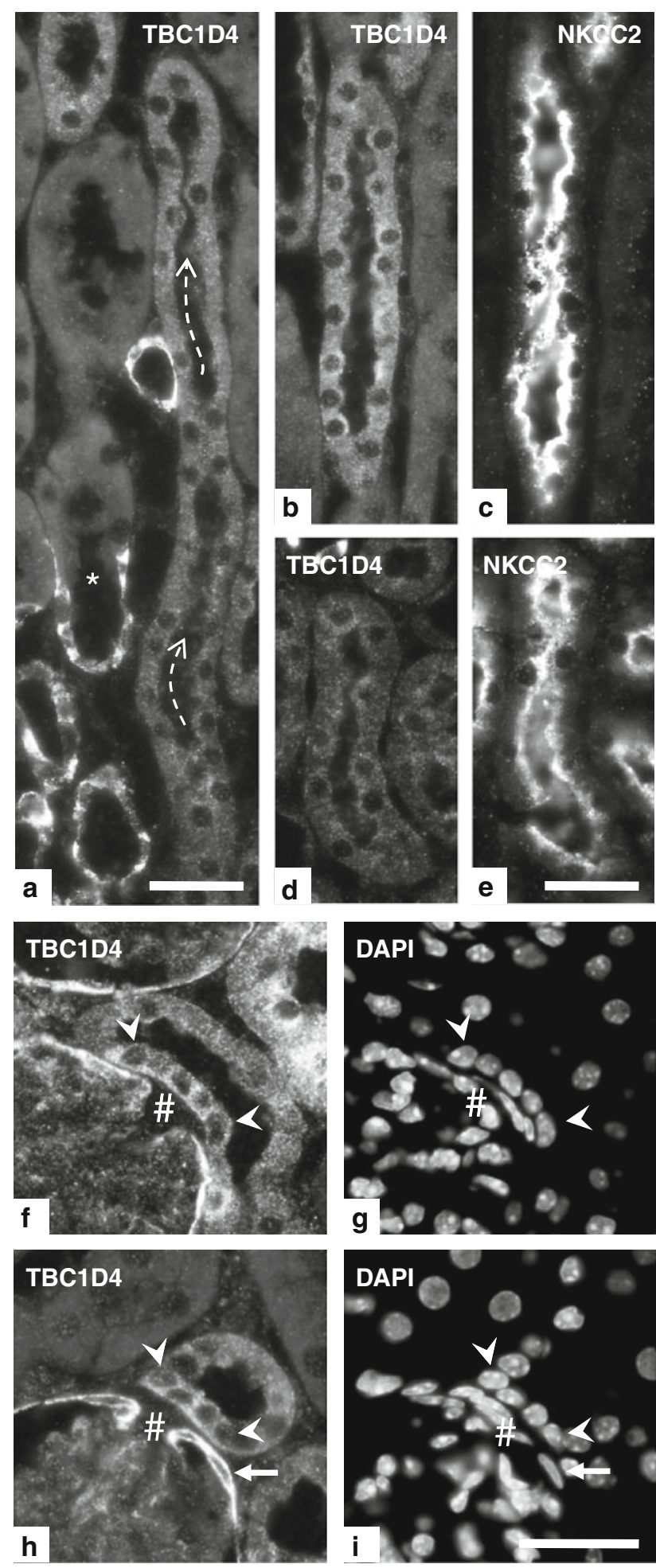

uptake. GLUT4 was reported to be expressed in renal vessels (Brosius et al. 1992), the glomerular tuft, the thick ascending limb (Chin et al. 1993), and other distal tubules (Albiston et al. 2011). The functional role of GLUT4 at these sites is unclear, but it may facilitate basolateral glucose uptake to fuel glycolytic ATP synthesis in cells with
4 Fig. 4 TBC1D4 abundance along the thick ascending limb (TAL). a TAL hit at the transition from the inner to the outer stripe. The asterisk marks the abrupt change from the TBC1D4-negative PST to the TBC1D4-positive DTL and hence indicates the border between the outer stripe (OS) and the inner stripe (IS). The increase of TBC1D4 abundance in tubular flow direction (arrows) of the TAL is even more pronounced when the staining intensities in cortical (b, c) and medullary (d, e) TAL are compared. (b-e) Consecutive cryosections immunostained with polyclonal antibodies against TBC1D4 and NKCC2. TBC1D4 is well detectable in the cytoplasm of the NKCC2-positive cortical TAL $(\mathbf{b}, \mathbf{c})$, but barely detectable in the NKCC2-positive medullary TAL (d, e). f-i Cryosections co-stained with a polyclonal antibody against TBC1D4 and with DAPI for detection of nuclear DNA. The macula densa is well recognizable by the closely packed DAPI-positive cell nuclei (arrowheads) directly adjacent to the mesangium (hash symbol) of the glomerulus. TBC1D4 abundance is more pronounced in the macula densa cells than in the surrounding TAL cells. Arrow strong TBC1D4-positive parietal epithelial cells of Bowman's capsule. Scale bars $\sim 30 \mu \mathrm{m}$

high transport activities. Among the renal tubules, the distal tubules have the highest density of mitochondria and of the $\mathrm{Na}^{+}-\mathrm{K}^{+}$-ATPase (Kriz and Kaissling 2008), they are rich in glycolytic enzymes such as hexokinase, pyruvate kinase and phosphofructokinase (Guder and Ross 1984), and they oxidize glucose at significant rates (Ross et al. 1986). The distal tubules do also express all components of the classical insulin-dependent signal transduction pathway, including the insulin receptor (Butlen et al. 1988) and PKB/Akt (Chabardes-Garonne et al. 2003; Pradervand et al. 2010). Therefore, it is conceivable that TBC1D4 may contribute to an insulin-dependent GLUT4 regulation in the kidney as it does in adipocytes and skeletal muscle cells.

Aside from the well-established TBC1D4 target GLUT4, recent studies suggested that TBC1D4 may also regulate the trafficking and function of renal ion and water transporting proteins. Alves et al. (2010) showed in renal COS and Madin-Darby canine kidney (MDCK) cells that TBC1D4 directly interacts with the $\alpha$-subunit of the $\mathrm{Na}^{+}$$\mathrm{K}^{+}$-ATPase, which is known to drive sodium transport across the basolateral plasma membrane of virtually all renal tubular epithelial cells. In addition, two recent studies provided evidence that TBC1D4 controls the cell surface abundance of the vasopressin-dependent water channel AQP2 (Jung and Kwon 2010; Kim et al. 2011) and the aldosterone-dependent sodium channel ENaC (Liang et al. 2010). The studies indicated that TBC1D4 may retain these proteins at intracellular sites until TBC1D4 becomes phosphorylated by serine/threonine kinases including the insulin-dependent PKB/Akt, adenosine monophosphatestimulated protein kinase (AMPK), the vasopressin-dependent protein kinase A (PKA) and the aldosterone-dependent serum and glucocorticoid induced kinase (SGK1) (Alves et al. 2010; Comellas et al. 2010; Jung and Kwon 2010; Kim et al. 2011; Liang et al. 2010). However, these studies were performed on cell lines in vitro. The current 
Fig. 5 Distribution of TBC1D4 along TAL, distal convoluted tubule (DCT) and connecting tubule (CNT). a-h Consecutive cryosections immunostained with antibodies against TBC1D4, NKCC2, NCC and CB28. a-c The sharp transition from the NKCC2-positive TAL to the NCC-positive DCT (arrowheads) coincides with an increase in the cytoplasmic TBC1D4 abundance in the epithelial cells. (d-f) TBC1D4 cytoplasmic protein abundance remains high in the early DCT (DCT1), but starts to decrease at the transition to the late DCT (DCT2). The abrupt change from high to very high abundance of CB D28 and the first appearance of CB28negative intercalated cells (arrow) mark the transition from DCT1 to DCT2. (g, h) The axial decrease of TBC1D4immunoreactivity is visible along the transition from DCT1 (intermediate CB28 staining, no intercalated cells), to DCT2 (strong CB28 staining, few CB28-negative intercalated cells), and finally to the CNT (intermediate CB28, many CB28 negative intercalated cells). Note the TBC1D4 immunoreactivity in both segment-specific and intercalated cells. Scale bars $\sim 30 \mu \mathrm{m}$
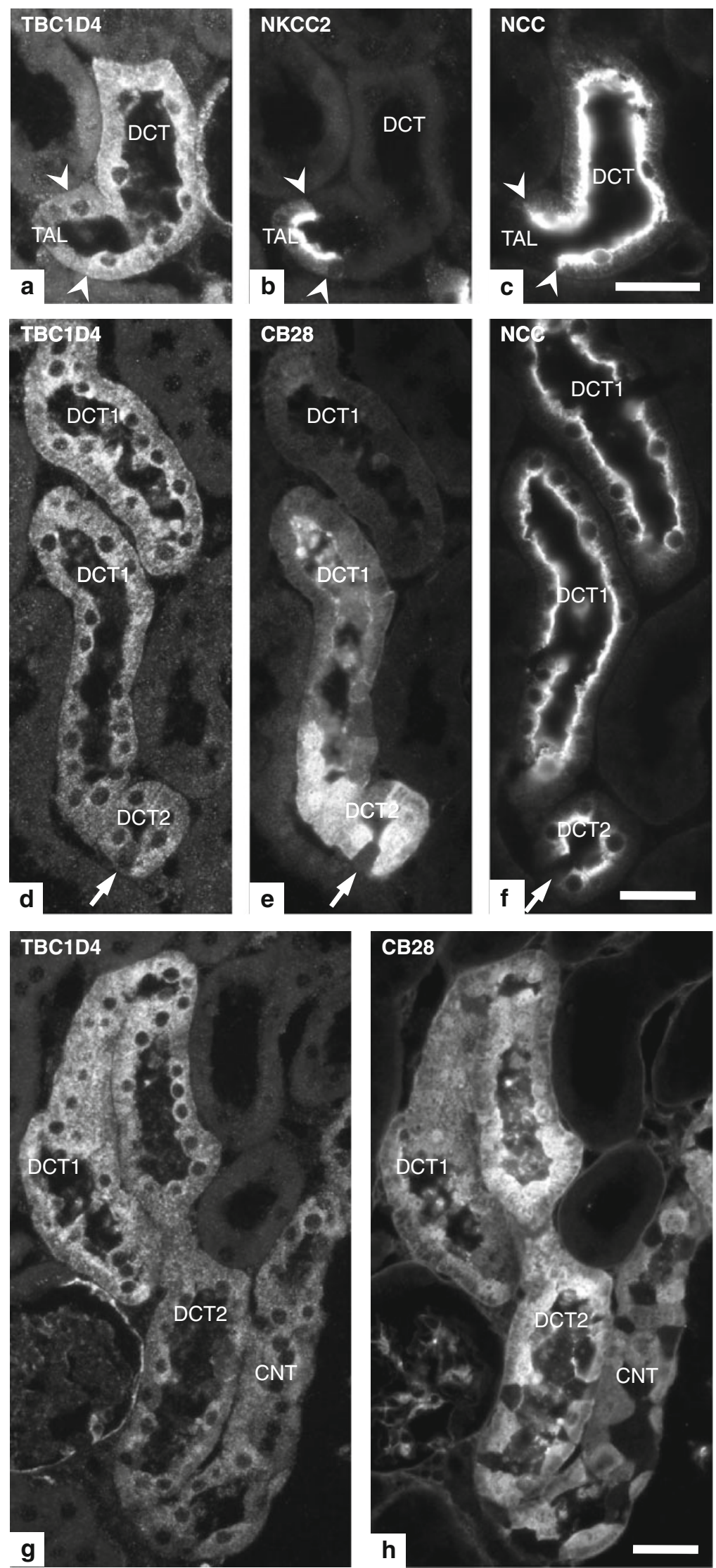

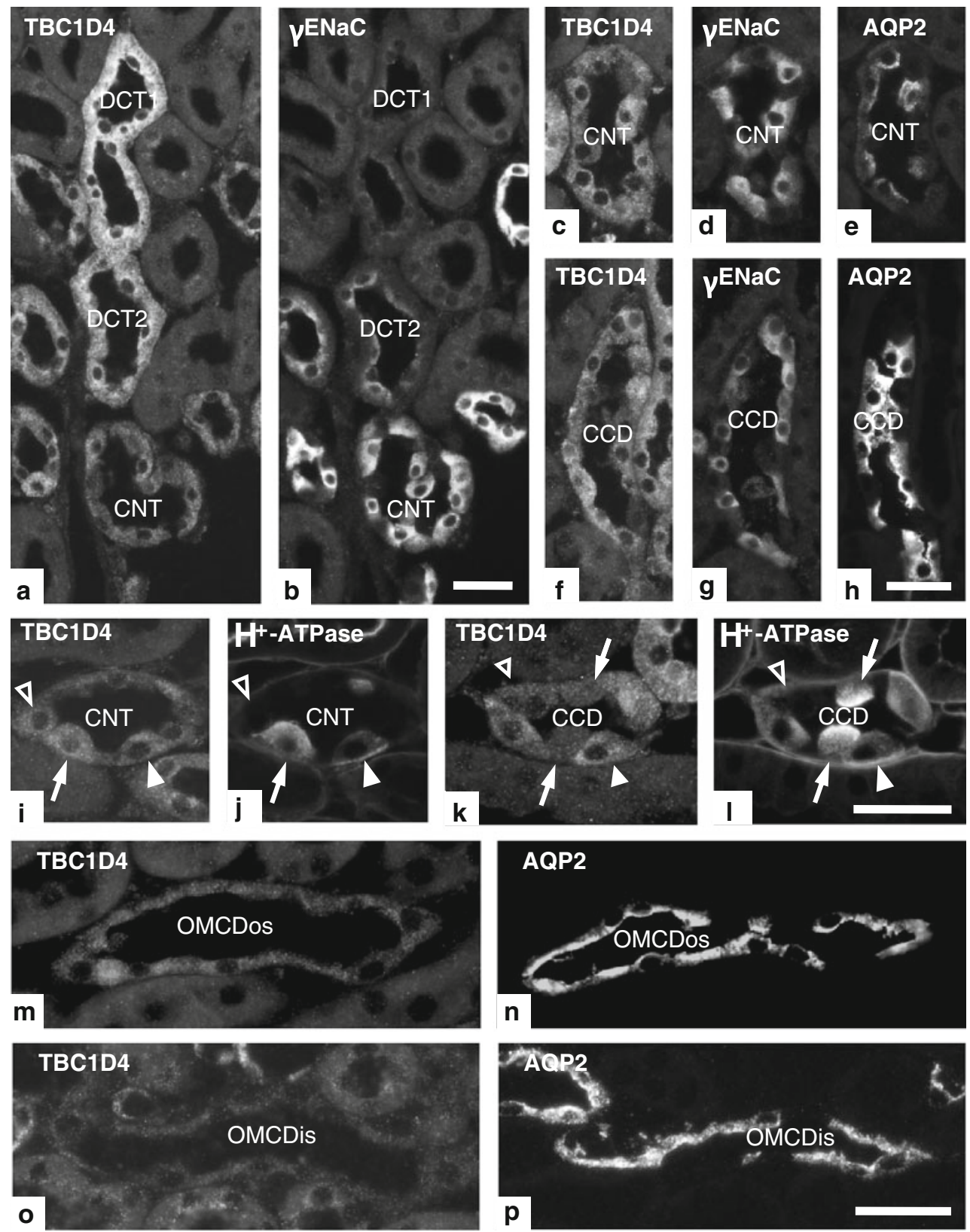

Fig. 6 Distribution of TBC1D4 in DCT, CNT, cortical collecting duct (CCD), and outer medullary collecting duct (OMCD). a, b Consecutive cryosections immunostained with antibodies against TBC1D4 and $\gamma \mathrm{ENaC}$. TBC1D4 is highly abundant in the $\gamma \mathrm{ENaC}-$ negative early DCT (DCT1) and the $\gamma \mathrm{ENaC}$-positive late DCT (DCT2), but is less abundant in the CNT. Note the predominant apical localization of $\gamma \mathrm{ENaC}$ in DCT2 and the pronounced intracellular localization of $\mathrm{ENaC}$ in $\mathrm{CNT}$, which is similar to previous reports (Loffing et al. 2000). Consecutive cryosections of CNT (c-e) and $\mathrm{CCD}(\mathbf{f}-\mathbf{h})$ immunostained for TBC1D4, $\gamma \mathrm{ENaC}$, and $\mathrm{AQP} 2$. TBC1D4 is abundant in CNT and CCD. Note that TBC1D4 is found in both the ENaC- and AQP2-positive segment-specific cells and the ENaC- and AQP2-negative intercalated cells. The higher levels of AQP2 expression discern the CCD from the CNT. Double

immunostainings in $\mathrm{CNT}(\mathbf{i}, \mathbf{j})$ and $\mathrm{CCD}(\mathbf{k}, \mathbf{l})$ for TBC1D4 and $\mathrm{H}^{+}$-ATPase confirm that TBC1D4 is abundant not only in the segment-specific CNT and CCD cells (open arrowheads), but also in type A (arrow) and type B (closed arrowhead) intercalated cells, with predominant apical and basolateral $\mathrm{H}^{+}$-ATPase localization, respectively. However, in the collecting duct, TBC1D4 abundance is rather low in the segment-specific and type A intercalated cells, while it remains high in the type $B$ intercalated cells. $\mathbf{m}-\mathbf{p}$ Consecutive cryosections of outer medullary collecting ducts for TBC1D4 and AQP2. In the outer stripe of the outer medulla, the collecting duct (OMCDos) shows very weak TBC1D4 immunostaining. In the collecting duct of the inner stripe (OMCDis), TBC1D4 is barely detectable and vanishes. Scale bars $\sim 30 \mu \mathrm{m}$ 
Fig. 7 Schematic representation of distribution and abundance of TBC1D4 along the mouse nephron and collecting duct. The green bar represents the distribution of TBC1D4. The other bars indicate the appearance or cessation of the used marker proteins. Shadings indicate different levels of immunostaining intensities. For abbreviations, segment definitions and further explanations, see "Materials and methods" and "Results"

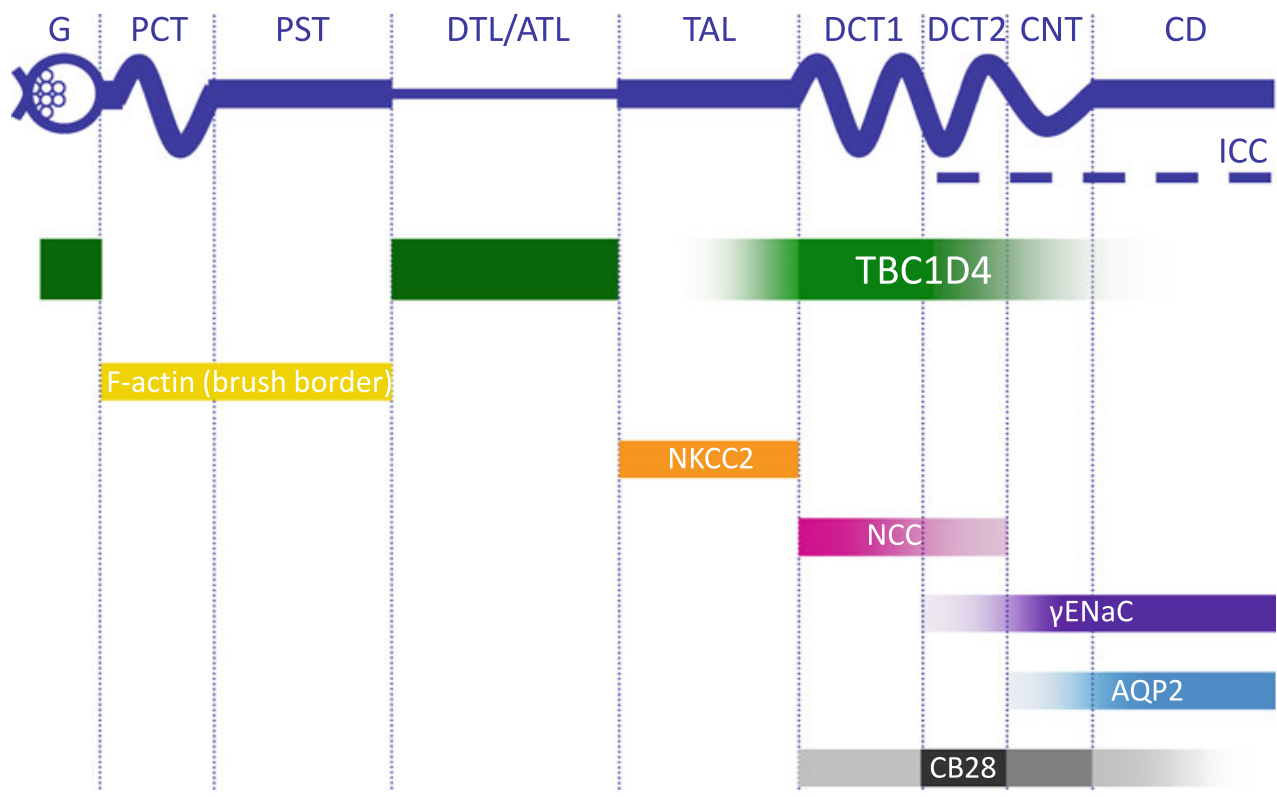

demonstration that TBC1D4 is highly abundant in the distal nephron and the collecting duct supports the idea that TBC1D4 controls the trafficking and function of the $\mathrm{Na}^{+}$$\mathrm{K}^{+}$-ATPase, ENaC and AQP2 not only in vitro but also in the kidney in vivo.

Interestingly, the abundance of TBC1D4 changes along the distal tubule. While the abundance of TBC1D4 is rather low in the medullary TAL, it increases along the cortical TAL to reach very high levels in the early DCT, before it starts to decrease again from the late DCT over the CNT to the CCD. The reasons for these axial differences are unclear, but they point to a differential regulation of TBC1D4 along the nephron, which might be relevant for the cell surface targeting of TBC1D4-regulated proteins. Notably, axial differences in the abundance and/or activity were described for the $\mathrm{Na}^{+}-\mathrm{K}^{+}$-ATPase, ENaC, and AQP2 (reviewed in (Loffing and Kaissling 2003). Although previous studies from others (Liang et al. 2010) and our laboratory indicated that aldosterone controls the expression of TBC1D4, it is unlikely that axial differences in the response to aldosterone explain the axial gradient of TBC1D4 along the distal tubule. In fact, aldosteronebinding, expression of the mineralocorticoid receptor and the transcriptional response to aldosterone appear to be rather homogenous along the CNT and CCD (Loffing and Korbmacher 2009).

TBC1D4 is also highly abundant in the thin limbs and parietal epithelial cells (PECs) of Bowman's capsule. The thin limbs play an important role for the urinary concentration mechanism by the countercurrent multiplication process. At least four different cells types were described, which specifically form either the descending or ascending limbs in short- and long-looped nephrons, respectively (Kriz and Kaissling 2008). As we did not see any unstained thin limb, we conclude that all subtypes of thin limb cells express TBC1D4. The functional role of TBC1D4 in these cells is unclear. The descending thin limbs express high levels of the water channel AQP1 (Sabolic et al. 1992) and the urea transporter UT-A2 (Wade et al. 2000) while the ascending thin limbs express the chloride channel ClC-K1 (Uchida et al. 1995). To what extend these channels and transporters are regulated by trafficking is unknown. However, it is remarkable that the thin limbs do also express high levels of the SNARE protein syntaxin 3, which is known to be involved in regulation of vesicular trafficking (Mandon et al. 1997). The PECs of Bowman's capsule form a rather thin squamous epithelium, which likely has a more dynamic cell turnover and cell metabolism as previously thought (Ohse et al. 2009). Consistent with a high metabolic activity, PECs express the glucose transporters GLUT4 and GLUT1 (Heilig et al. 1995), which are both regulated by TBC1D4 (Mendes et al. 2010).

We just started to learn about the in vivo role of TBC1D4 in the regulation of glucose homeostasis. Patients with type-2 diabetes were shown to have reduced levels of TBC1D4 phosphorylation in skeletal muscle cells, which may contribute to reduced cell surface targeting of GLUT4 (Karlsson et al. 2005). Likewise, transgenic mice with targeted inactivation of the phosphorylation site Thr649 in TBC1D4 exhibit a reduced GLUT4 abundance and lowered glucose uptake into skeletal muscle cells, leading to reduced insulin-sensitivity and delayed glucose disposal (Chen et al. 2011). Moreover, patients with a truncated form of TBC1D4, due to a premature stop-codon in the 
TBC1D4 gene, show severe insulin-resistance with hyperglycemia and acanthosis nigrans (Dash et al. 2009). The renal phenotype of the mouse model and the patients has not yet been studied. The detailed description of the intrarenal distribution of TBC1D4 may now provide a basis on which further studies could address the in vivo role of TBC1D4 in the kidney.

Thus, TBC1D4 is expressed in the kidney in many cell types in which it may contribute to the regulation of several renal transport proteins including GLUT1, GLUT4, $\mathrm{Na}^{+}$$\mathrm{K}^{+}$-ATPase, ENaC, and AQP2. The fact that TBC1D4 is not detectable in all renal cell types indicates that TBC1D4 is not a ubiquitous regulator of membrane trafficking, but may have tissue- and cell type-specific functions. In the kidney, TBC1D4 may control renal ion and water handling and hence contribute to the control of extracellular fluid homeostasis.

Acknowledgments The study is part of the M.D. thesis of Natascha Lier. The study was supported by Grants from the Swiss National Science Foundation 310000-122243/1 (to JL) and the Novartis Foundation (to JL). The laboratory of JL is also supported by the National Centre of Competence in Research (NCCR) Kidney.CH and the Zurich Center for Integrative Human Physiology (ZIHP). We gratefully acknowledge the expert technical help of Monique Carrel. Initial immunohistochemical studies were also performed with antibodies against TBC1D4 (AS160), which have been kindly provided by Dr. Gustav E. Lienhard (Dartmouth Medical School, Hanover, NH, USA).

\section{References}

Albiston AL, Yeatman HR, Pham V, Fuller SJ, Diwakarla S, Fernando RN, Chai SY (2011) Distinct distribution of GLUT4 and insulin regulated aminopeptidase in the mouse kidney. Regul Pept 166:83-89

Alves DS, Farr GA, Seo-Mayer P, Caplan MJ (2010) AS160 associates with the $\mathrm{Na}+, \mathrm{K}+-\mathrm{ATPa} e$ and mediates the adenosine monophosphate-stimulated protein kinase-dependent regulation of sodium pump surface expression. Mol Biol Cell 21:4400-4408

Barr F, Lambright DG (2010) Rab GEFs and GAPs. Curr Opin Cell Biol 22:461-470

Baus D, Heermeier K, De Hoop M, Metz-Weidmann C, Gassenhuber J, Dittrich W, Welte S, Tennagels N (2008) Identification of a novel AS160 splice variant that regulates GLUT4 translocation and glucose-uptake in rat muscle cells. Cell Signal 20:2237-2246

Brosius FC 3rd, Briggs JP, Marcus RG, Barac-Nieto M, Charron MJ (1992) Insulin-responsive glucose transporter expression in renal microvessels and glomeruli. Kidney Int 42:1086-1092

Brown D, Lydon J, McLaughlin M, Stuart-Tilley A, Tyszkowski R, Alper S (1996) Antigen retrieval in cryostat tissue sections and cultured cells by treatment with sodium dodecyl sulfate (SDS). Histochem Cell Biol 105:261-267

Busque SM, Wagner CA (2009) Potassium restriction, high protein intake, and metabolic acidosis increase expression of the glutamine transporter SNAT3 (Slc38a3) in mouse kidney. Am J Physiol Renal Physiol 297:F440-F450

Butlen D, Vadrot S, Roseau S, Morel F (1988) Insulin receptors along the rat nephron: [125I] insulin binding in microdissected glomeruli and tubules. Pflugers Arch 412:604-612
Chabardes-Garonne D, Mejean A, Aude JC, Cheval L, Di Stefano A, Gaillard MC, Imbert-Teboul M, Wittner M, Balian C, Anthouard V, Robert C, Segurens B, Wincker P, Weissenbach J, Doucet A, Elalouf JM (2003) A panoramic view of gene expression in the human kidney. Proc Natl Acad Sci USA 100:13710-13715

Chen S, Wasserman DH, MacKintosh C, Sakamoto K (2011) Mice with AS160/TBC1D4-Thr649Ala knockin mutation are glucose intolerant with reduced insulin sensitivity and altered GLUT4 trafficking. Cell Metab 13:68-79

Chin E, Zhou J, Bondy C (1993) Anatomical and developmental patterns of facilitative glucose transporter gene expression in the rat kidney. J Clin Invest 91:1810-1815

Comellas AP, Kelly AM, Trejo HE, Briva A, Lee J, Sznajder JI, Dada LA (2010) Insulin regulates alveolar epithelial function by inducing $\mathrm{Na}+/ \mathrm{K}+-$ ATPase translocation to the plasma membrane in a process mediated by the action of Akt. J Cell Sci 123:1343-1351

Dash S, Sano H, Rochford JJ, Semple RK, Yeo G, Hyden CS, Soos MA, Clark J, Rodin A, Langenberg C, Druet C, Fawcett KA, Tung YC, Wareham NJ, Barroso I, Lienhard GE, O'Rahilly S, Savage DB (2009) A truncation mutation in TBC1D4 in a family with acanthosis nigricans and postprandial hyperinsulinemia. Proc Natl Acad Sci USA 106:9350-9355

Eguez L, Lee A, Chavez JA, Miinea CP, Kane S, Lienhard GE, McGraw TE (2005) Full intracellular retention of GLUT4 requires AS160 Rab GTPase activating protein. Cell Metab 2:263-272

Feraille E, Doucet A (2001) Sodium-potassium-adenosinetriphosphatase-dependent sodium transport in the kidney: hormonal control. Physiol Rev 81:345-418

Frasa MA, Koessmeier KT, Ahmadian MR, Braga VM (2012) Illuminating the functional and structural repertoire of human TBC/RABGAPs. Nat Rev Mol Cell Biol 13:67-73

Guder WG, Ross BD (1984) Enzyme distribution along the nephron. Kidney Int 26:101-111

Heilig C, Zaloga C, Lee M, Zhao X, Riser B, Brosius F, Cortes P (1995) Immunogold localization of high-affinity glucose transporter isoforms in normal rat kidney. Lab Invest 73:674-684

Hemken P, Guo XL, Wang ZQ, Zhang K, Gluck S (1992) Immunologic evidence that vacuolar $\mathrm{H}+$ ATPases with heterogeneous forms of $\mathrm{Mr}=31,000$ subunit have different membrane distributions in mammalian kidney. J Biol Chem 267:9948-9957

Ishikura S, Bilan PJ, Klip A (2007) Rabs 8A and 14 are targets of the insulin-regulated Rab-GAP AS160 regulating GLUT4 traffic in muscle cells. Biochem Biophys Res Commun 353:1074-1079

Jung HJ, Kwon TH (2010) Membrane trafficking of collecting duct water channel protein AQP2 regulated by Akt/AS160. Electrolyte Blood Press 8:59-65

Kane S, Sano H, Liu SC, Asara JM, Lane WS, Garner CC, Lienhard GE (2002) A method to identify serine kinase substrates. Akt phosphorylates a novel adipocyte protein with a Rab GTPaseactivating protein (GAP) domain. J Biol Chem 277:22115-22118

Karlsson HK, Zierath JR, Kane S, Krook A, Lienhard GE, WallbergHenriksson H (2005) Insulin-stimulated phosphorylation of the Akt substrate AS160 is impaired in skeletal muscle of type 2 diabetic subjects. Diabetes 54:1692-1697

Kim J, Kim YH, Cha JH, Tisher CC, Madsen KM (1999) Intercalated cell subtypes in connecting tubule and cortical collecting duct of rat and mouse. J Am Soc Nephrol 10:1-12

Kim HY, Choi HJ, Lim JS, Park EJ, Jung HJ, Lee YJ, Kim SY, Kwon TH (2011) Emerging role of Akt substrate protein AS160 in the regulation of AQP2 translocation. Am J Physiol Renal Physiol 301:F151-F161

Kishore BK, Mandon B, Oza NB, DiGiovanni SR, Coleman RA, Ostrowski NL, Wade JB, Knepper MA (1996) Rat renal arcade 
segment expresses vasopressin-regulated water channel and vasopressin V2 receptor. J Clin Invest 97:2763-2771

Kriz W, Kaissling B (2008) Structural organization of the mammalian kidney. In: Alpern RJ, Hebert SC (eds) Seldin and Giebisch's The Kidney Physiology and Pathophysiology, vol 1, Academic PressBurlington, San Diego, pp 479-564

Larance M, Ramm G, Stockli J, van Dam EM, Winata S, Wasinger V, Simpson F, Graham M, Junutula JR, Guilhaus M, James DE (2005) Characterization of the role of the Rab GTPase-activating protein AS160 in insulin-regulated GLUT4 trafficking. J Biol Chem 280:37803-37813

Liang X, Butterworth MB, Peters KW, Frizzell RA (2010) AS160 modulates aldosterone-stimulated epithelial sodium channel forward trafficking. Mol Biol Cell 21:2024-2033

Lim YS, Chua CE, Tang BL (2011) Rabs and other small GTPases in ciliary transport. Biol Cell 103:209-221

Loffing J, Kaissling B (2003) Sodium and calcium transport pathways along the mammalian distal nephron: from rabbit to human. Am J Physiol Renal Physiol 284:F628-F643

Loffing J, Korbmacher C (2009) Regulated sodium transport in the renal connecting tubule $(\mathrm{CNT})$ via the epithelial sodium channel (ENaC). Pflugers Arch 458:111-135

Loffing J, Pietri L, Aregger F, Bloch-Faure M, Ziegler U, Meneton P, Rossier BC, Kaissling B (2000) Differential subcellular localization of $\mathrm{ENaC}$ subunits in mouse kidney in response to highand low-Na diets. Am J Physiol Renal Physiol 279:F252-F258

Loffing J, Loffing-Cueni D, Valderrabano V, Klausli L, Hebert SC, Rossier BC, Hoenderop JG, Bindels RJ, Kaissling B (2001) Distribution of transcellular calcium and sodium transport pathways along mouse distal nephron. Am J Physiol Renal Physiol 281:F1021-F1027

Loffing J, Vallon V, Loffing-Cueni D, Aregger F, Richter K, Pietri L, Bloch-Faure M, Hoenderop JG, Shull GE, Meneton P, Kaissling $\mathrm{B}(2004)$ Altered renal distal tubule structure and renal $\mathrm{Na}(+)$ and $\mathrm{Ca}(2+)$ handling in a mouse model for Gitelman's syndrome. J Am Soc Nephrol 15:2276-2288

Mandon B, Nielsen S, Kishore BK, Knepper MA (1997) Expression of syntaxins in rat kidney. Am J Physiol 273:F718-F730

Mather A, Pollock C (2011) Glucose handling by the kidney. Kidney Int Suppl:S1-6

Mendes AI, Matos P, Moniz S, Jordan P (2010) Protein kinase WNK1 promotes cell surface expression of glucose transporter GLUT1 by regulating a Tre-2/USP6-BUB2-Cdc16 domain family member 4 (TBC1D4)-Rab8A complex. J Biol Chem 285:3911739126

Miinea CP, Sano H, Kane S, Sano E, Fukuda M, Peranen J, Lane WS, Lienhard GE (2005) AS160, the Akt substrate regulating GLUT4 translocation, has a functional Rab GTPase-activating protein domain. Biochem J 391:87-93

Mount DB (2006) Membrane trafficking and the regulation of NKCC2. Am J Physiol Renal Physiol 290:F606-F607

Murer H, Hernando N, Forster I, Biber J (2003) Regulation of Na/Pi transporter in the proximal tubule. Annu Rev Physiol 65:531542

Mutig K, Saritas T, Uchida S, Kahl T, Borowski T, Paliege A, Bohlick A, Bleich M, Shan Q, Bachmann S (2010) Short-term stimulation of the thiazide-sensitive $\mathrm{Na}+-\mathrm{Cl}-$ cotransporter by vasopressin involves phosphorylation and membrane translocation. Am J Physiol Renal Physiol 298:F502-F509

Nagase T, Ishikawa K, Suyama M, Kikuno R, Miyajima N, Tanaka A, Kotani H, Nomura N, Ohara O (1998) Prediction of the coding sequences of unidentified human genes. XI. The complete sequences of 100 new cDNA clones from brain which code for large proteins in vitro. DNA Res 5:277-286

Nielsen S, Frokiaer J, Marples D, Kwon TH, Agre P, Knepper MA (2002) Aquaporins in the kidney: from molecules to medicine. Physiol Rev 82:205-244

Ohse T, Pippin JW, Chang AM, Krofft RD, Miner JH, Vaughan MR, Shankland SJ (2009) The enigmatic parietal epithelial cell is finally getting noticed: a review. Kidney Int 76:1225-1238

Pradervand S, Zuber Mercier A, Centeno G, Bonny O, Firsov D (2010) A comprehensive analysis of gene expression profiles in distal parts of the mouse renal tubule. Pflugers Arch 460:925952

Reilly RF, Ellison DH (2000) Mammalian distal tubule: physiology, pathophysiology, and molecular anatomy. Physiol Rev 80:277313

Ross BD, Espinal J, Silva P (1986) Glucose metabolism in renal tubular function. Kidney Int 29:54-67

Sabolic I, Valenti G, Verbavatz JM, Van Hoek AN, Verkman AS, Ausiello DA, Brown D (1992) Localization of the CHIP28 water channel in rat kidney. Am J Physiol 263:C1225-C1233

Sandberg MB, Riquier AD, Pihakaski-Maunsbach K, McDonough AA, Maunsbach AB (2007) ANG II provokes acute trafficking of distal tubule $\mathrm{Na}+-\mathrm{Cl}(-)$ cotransporter to apical membrane. Am J Physiol Renal Physiol 293:F662-F669

Sano H, Kane S, Sano E, Miinea CP, Asara JM, Lane WS, Garner CW, Lienhard GE (2003) Insulin-stimulated phosphorylation of a Rab GTPase-activating protein regulates GLUT4 translocation. J Biol Chem 278:14599-14602

Sano H, Roach WG, Peck GR, Fukuda M, Lienhard GE (2008) Rab10 in insulin-stimulated GLUT4 translocation. Biochem J 411:89-95

Schmitt R, Ellison DH, Farman N, Rossier BC, Reilly RF, Reeves WB, Oberbaumer I, Tapp R, Bachmann S (1999) Developmental expression of sodium entry pathways in rat nephron. Am J Physiol 276:F367-F381

Stenmark H, Olkkonen VM (2001) The Rab GTPase family. Genome Biol 2:REVIEWS3007

Takai Y, Sasaki T, Matozaki T (2001) Small GTP-binding proteins. Physiol Rev 81:153-208

Uchida S, Sasaki S, Nitta K, Uchida K, Horita S, Nihei H, Marumo F (1995) Localization and functional characterization of rat kidney-specific chloride channel, ClC-K1. J Clin Invest 95:104-113

Wade JB, Lee AJ, Liu J, Ecelbarger CA, Mitchell C, Bradford AD, Terris J, Kim GH, Knepper MA (2000) UT-A2: a 55 kDa urea transporter in thin descending limb whose abundance is regulated by vasopressin. Am J Physiol Renal Physiol 278:F52-F62

Wagner CA, Finberg KE, Breton S, Marshansky V, Brown D, Geibel JP (2004) Renal vacuolar H+-ATPase. Physiol Rev 84:12631314

Wagner CA, Loffing-Cueni D, Yan Q, Schulz N, Fakitsas P, Carrel M, Wang T, Verrey F, Geibel JP, Giebisch G, Hebert SC, Loffing J (2008) Mouse model of type II Bartter's syndrome. II. Altered expression of renal sodium- and water-transporting proteins. Am J Physiol Renal Physiol 294:F1373-F1380

Werner M, Von Wasielewski R, Komminoth P (1996) Antigen retrieval, signal amplification and intensification in immunohistochemistry. Histochem Cell Biol 105:253-260

White RA, Pasztor LM, Richardson PM, Zon LI (2000) The gene encoding TBC1D1 with homology to the tre-2/USP6 oncogene, BUB2, and cdc16 maps to mouse chromosome 5 and human chromosome 4. Cytogenet Cell Genet 89:272-275 